\title{
Oral nanoemulsions of candesartan cilexetil: formulation, characterization and in vitro drug release studies
}

\author{
Halah Hussein Ali ${ }^{*}$ and Ahmed Abbas Hussein
}

\begin{abstract}
Nanoemulsion is considered to be a new and exciting field of research that seeks to exploit the attractive properties of components to improve oral delivery of drugs like candesartan cilexetil used in the management of chronic diseases. Candesartan cilexetil is a lipophilic acidic drug with a half-life of about (5-10) hour and absolute bioavailability of (14-40\%). For this reason, the study target was to formulate and characterize candesartan cilexetil nanoemulsions that could improve solubility, dissolution and stability of the lipophilic drug candesartan cilexetil. The solubility of candesartan cilexetil was checked in various vehicles in order to choose the best solubilizing components for building up an efficient nanoemulsion based on regulating hydrophilic/lipophilic balance (HLB) value above 10, and then pseudo-ternary phase diagram was used as a useful tool to evaluate the nanoemulsion domain. The nanoemulsion formulations were prepared using various concentrations of cinnamon oil, tween 80 with poloxamer mixture and transcutol HP as oil, surfactant mixture and co-surfactant respectively by aqueous titration method at surfactant/co-surfactant ratios of 3:1 and 4:1 and varying the type of poloxamer in each ratio. The prepared nanoemulsions were tested for nanodispersion stability studies, droplet size distribution, polydispersity index, zeta potential, viscosity, filter paper spreadability, dye miscibility, electroconductivity, pH, percent transmittance, surface tension, refractive index, morphology and drug dissolution. It was found that release rate and extent for all prepared nanoformulations were significantly higher $(p<0.05)$ than marketed tablet formulation as well as plain drug powder.

The results demonstrated that, the potential use of this system is a perfect technique for improving solubility and dissolution of candesartan cilexetil.
\end{abstract}

Keywords: Candesartan cilexetil, Solubility, Pseudo-ternary phase diagram, Nanoemulsion, Drug dissolution, Stability

\section{Background}

Candesartan cilexetil (CC) is a selective, reversible and competitive angiotensin II type-1 (AT1) receptor blocker belonging to class II in biopharmaceutical drug classification system (BCS) with absolute bioavailability for candesartan of about (14-40\%) and molecular weight (MWT) of 610.66 gram "g"/mole used in management of many coronary heart diseases (Sweetman 2009; Budavari et al. 1989). It contains two acidic functional groups: a carboxyl and tetrazole moieties and its pKa values were calculated to be 4.22 in its unionized form and 4.24 in its ionized form (Beale et al. 2010; Bandyopadhyay et al. 2013). The

\footnotetext{
* Correspondence: halahpharma@yahoo.com

Department of Pharmaceutics, College of Pharmacy, Baghdad University, Baghdad, Iraq
}

(c) The Author(s). 2017 Open Access This article is distributed under the terms of the Creative Commons Attribution 4.0 International License (http://creativecommons.org/licenses/by/4.0/), which permits unrestricted use, distribution, and reproduction in any medium, provided you give appropriate credit to the original author(s) and the source, provide a link to the Creative Commons license, and indicate if changes were made.

$\mathrm{CC}$ is a racemic mixture containing one chiral center at the ester group. After CC is taken orally, it undergoes hydrolysis at the ester linkage to form the active drug, candesartan, which is a chiral. Candesartan in turns is converted to one inactive metabolite (Darwhekar et al. 2012; Moffat et al. 2011). The terminal elimination half-life of CC is about (5-10 h) with total plasma clearance of $0.37 \mathrm{milliliter} / \mathrm{min} /$ " $\mathrm{ml} / \mathrm{min} / \mathrm{kg}$ " and renal clearance of $0.19 \mathrm{ml} / \mathrm{min} / \mathrm{kg}$ (Husain et al. 2011; Kolesar and Vermeulen 2016).

When developing an oral liquid dosage form, consideration is first given to the characteristics of the active ingredient such as solubility, $\mathrm{pH}$ stability of a drug and an acceptable taste. Different techniques like solid dispersions, liposomes, complexation with cyclodextrins,

\section{Springer Open}


use of permeation enhancers and micronizations were tried to overcome some solubility and permeability issues (Banker et al. 2002). However, reduction in particle sizes almost always increasing rate of solution. It was remarked that smaller particle size leads to a greater rate of dissolution, since the proportion of surface area exposed to the solvent compared to the volume of the particles increases with decreasing particle diameter (Patel et al. 2011).

Nanoemulsions (NEs) are thermodynamically stable dispersions of deformable nanoscale droplets within the range of (10-200 nanometer " $\mathrm{nm}$ ") that can pose specific physicochemical properties such as transparency, optical isotropy, low viscosity and does not have the tendency to coalesce due to the presence of a stabilizing surfactant (Sainsbury et al. 2014; Narang et al. 2007). Accordingly, NEs are considered particular tools for chemical and pharmaceutical applications (Gupta et al. 2010). Their small elastic droplets impart them a higher stability because the Brownian motion and consequently the diffusion rate is higher than the sedimentation or creaming rate induced by the gravity force (Setya et al. 2014).

The objectives of the present investigation were, firstly, to formulate and characterize NE of varying proportions of cinnamon oil, tween 80 with different poloxamer type mixture, transcutol HP with minimum surfactant and co-surfactant concentrations that could improve solubility, dissolution and stability of the lipophilic drug CC; and secondly, to investigate the effects of composition on the physicochemical properties of each nanosystem prepared for formula optimization.

\section{Materials and methods Materials}

Candesartan cilexetil, poloxamer 188, poloxamer 407 and poloxamer 338 were kindly purchased from Shenzhen Nexconn PharmaTechs, LTD. (China). Cinnamon oil was brought from Now food (USA). Tween 80 was purchased from Pure chemistry (Germany). Transcutol HP was purchased from Gattefosse Corporation (USA). All other chemicals used were of analytical grade.

\section{Methods \\ Solubility studies}

Solubility of CC was checked in various vehicles in order to choose the best solubilizing components for building up an efficient NE based on regulating the HLB value above 10 , then pseudo-ternary phase diagram was used as a useful tool to evaluate the NE domain at surfactant: co-surfactant mixture (Smix) ratios: $3: 1$ and 4:1. To select the best solvents for dissolving $\mathrm{CC}$ in liquid medication, solubility studies of $\mathrm{CC}$ were constructed in a number of oils, surfactants and co-surfactants at $25^{\circ} \mathrm{C}$.
Saturated solutions were prepared by adding an excess of CC to the vehicles and shaking them on the water bath shaker (GFL, karl Kolb, Germany) for 48 hour (h) under constant vibration. After this period, the solutions were filtered through 0.45 micro meter $(\mu \mathrm{m})$ Millipore filter, suitably diluted with ethanol and analyzed by Ultraviolet/Visible (UV/Vis) spectrophotometer (UV6100 PC, EMC lab, Germany) at $\lambda_{\text {max }}$ of CC (255 nm). Three determinations were carried out for each sample to calculate the solubility of CC (Shukla et al. 2016; Domalapally et al. 2014).

\section{Construction of pseudo-ternary phase diagrams}

After screening various oils, surfactants and co-surfactants NEs components used were cinnamon oil, tween 80 with poloxamer as a mixed surfactant and transcutol HP as a co-surfactant and varying the type of poloxamer in each ratio. Mixtures were divided into three different systems. System A was consisting of cinnamon oil, tween 80 with poloxamer 188 mixture and transcutol $\mathrm{HP}$, system B contained cinnamon oil, tween 80 with poloxamer 407 mixture and transcutol HP and system $\mathrm{C}$ was composed of cinnamon oil, tween 80 with poloxamer 338 mixture and transcutol HP. Surfactant mixture and co-surfactant were mixed in different weight ratios which include: 3:1 and $4: 1$ by using aqueous titration method at a temperature of $25{ }^{\circ} \mathrm{C}$, which matches the common requirements of preparation, storage and application of NEs (Selvam et al. 2013).

For each phase diagram, cinnamon oil and specific Smix ratio were mixed thoroughly in different weight ratios $(1: 9,2: 8,3: 7,4: 6,5: 5,6: 4,7: 3,8: 2$ and 9:1) in glass vials in order to delineate the boundaries of phases precisely. Water was added in drop wise manner for each combination of oil and Smix separately under gentle magnetic agitation until a stable transparent system was formed. The resulting type of NE whether it is oil in water $(\mathrm{o} / \mathrm{w})$ or water in oil (w/o) could be further investigated by diluting about $1 \mathrm{ml}$ of $\mathrm{NE}$ with deionized water and monitored for clarity. If the formed solution remained clear, it indicates o/w type (Kumar et al. 2009).

\section{Preparation of drug-loaded nanoemulsions}

The drug, CC, was combined with each formulation prepared at the dose of : 8 milligram $(\mathrm{mg})$ of $\mathrm{CC} / 4-5 \mathrm{ml}$ of NE. Briefly, about $8 \mathrm{mg}$ of CC was dissolved in cinnamon oil, and then the appropriate amounts of surfactant mixture and co-surfactant were added and vortex for about 5 min using vortex mixer (Labinco L46, CAT.NO.46000, Netherland). Deionized water was added sequentially with gentle magnetic stirring (CB 162 heat-stir, Stuart, Copley scientific, U.K.) until a homogenous clear solution was achieved (Souto et al. 2011). Three binary mixtures of surfactant systems were obtained as follow: tween 80 with 
poloxamer 188, tween 80 with poloxamer 407 and tween 80 with poloxamer 338. The HLB number of each mixed surfactant system (HLB mix $)$ was calculated by using Eqs. 1, 2 and 3 (Sarker 2013; Americas 1984):

$$
\begin{aligned}
& \left.H L B_{\text {mix }}=\left(f \times H L B_{A}\right)+\left[(1-f) \times H L B_{B}\right)\right] \\
& \text { Surfactant A } \%=\frac{100\left(\mathrm{X}-\mathrm{HLB}_{\mathrm{B}}\right)}{\mathrm{HLB}_{\mathrm{A}}-\mathrm{HLB}_{\mathrm{B}}} \\
& \text { Surfactant B } \%=100 \text {-Surfactant A } \%
\end{aligned}
$$

Where: HLB ${ }_{A}$ and HLB ${ }_{B}$ are HLB values of surfactant $A$ and surfactant $B, f_{A}$ and $f_{B}$ are the weight fractions of surfactant $A$ and surfactant $B$, respectively. The $H_{L B} B_{\text {mix }}$ required in this study was above 10 . In each Smix ratio, tween 80 was mixed with poloxamer in specific ratios which were: 13:1, 4:1 and 11:1 for poloxamer 188, 407 and 338 respectively, so that HLB was held constant as 16 and when it was mixed with transcutol HP in 3:1 and 4:1 ratios, it resulted in final HLB values of 13.075 and 13.660 , respectively.

\section{Evaluations of prepared candesartan cilexetil nanoemulsions \\ Nanodispersion stability studies}

Centrifuge test The NE formulations were all centrifuged at 3500 revolutions per minute (rpm) for $30 \mathrm{~min}$. These formulations that overcome this test and maintain a monophasic state was taken for heating/cooling cycles test (Ankith et al. 2013).

Heating/cooling cycle test Six cycles between refrigerator temperature of $4{ }^{\circ} \mathrm{C}$ and an oven temperature of $45^{\circ} \mathrm{C}$ for $48 \mathrm{~h}$ storage at each temperature were made. The formulations that pass this test were subjected to freezingthawing cycle's test (Ankith et al. 2013).

Freezing/thawing cycles test This test was done for all NEs prepared at a temperature between $\left(-21\right.$ and $\left.+25^{\circ} \mathrm{C}\right)$. Formulations that remain clear and not separate were selected for further studies (Sureshkumar et al. 2015).

\section{Determination of droplet size distribution and polydispersity index}

Droplet sizes distribution measurement and polydispersity index (PDI) determination were performed for stable CC NE formulations by using particle size analyzer instrument (Brookhaven Corp 90 Plus, NY, USA) which analyzes the fluctuations in light scattering due to Brownian motion of particles using helium-neon gas monitored at $25{ }^{\circ} \mathrm{C}$ and $90^{\circ}$ angle having intensity of 4 micro watt $(\mathrm{Mw})$ as a light source. This equipment provides 18 millimeter $(\mathrm{mm})$ laser width (Troncoso et al. 2011).

\section{Zeta potential measurement}

The zeta potential value determination was made by using zeta plus instrument (Brookhaven Zeta Plus, Holtsville, NY 11742-1832, USA) which relied on measuring electrophoretic mobility in micro meter per second " $\mu \mathrm{m} / \mathrm{s}$ " and converted to zeta potential by in-built software using Helmholtz-Smoluchowski equation (Tiwari and Amiji 2006). Particles of zeta potentials more positive than $(+30$ millivolt " $\mathrm{mV}$ ") are normally considered stable. Particles of zeta potentials more negative than $(-30 \mathrm{mV})$ are normally considered stable (Gupta et al. 2011).

\section{Viscosity determination, filter paper test, dye miscibility} test and electroconductivity measurement

All prepared NEs were evaluated for various tests including: viscosity, filter paper spreadability, dye miscibility and electroconductivity. Measurements were carried out to ascertain if the outer phase is water continuous or oil continuous. Rheological properties of NE formulations were determined using digital viscometer (NDJ-5S, U.K.) and applying spindle- 1 at $25 \pm 1{ }^{\circ} \mathrm{C}$. Spindle was inserted into $40 \mathrm{ml}$ sample of prepared NE put in a graduated cylinder and rotated at different speeds that were: 6,12 , 30 and $60 \mathrm{rpm}$. The experiment was done in triplicate for each sample and the results were presented as mean \pm Standard deviation "SD" (Srilatha et al. 2013).

Filter paper test is based on the fact that an o/w NE will spread out rapidly when dropped onto filter paper. In contrast, a w/o NE will migrate only slowly (Jaiswal et al. 2015). On the other hand, a water soluble dye (methyl orange) was mixed with each CC NE formula. If the dye mixed with NE homogeneously without precipitation, this indicates that the NE structure is o/w (Domalapally et al. 2014).

Furthermore, Electrical conductivity of NE formulations was measured by using digital electroconductometer (DDS 307, Germany). The instrument electrode was immersed in $10 \mathrm{ml}$ of each formulation and reading was recorded at $25 \pm 1{ }^{\circ} \mathrm{C}$. All measurements were made in triplicate manner (Xu et al. 2011).

\section{Measurement of $\mathrm{pH}$}

The $\mathrm{pH}$ of all prepared $\mathrm{CC}$ NEs was measured via the $\mathrm{pH}$ meter instrument (BP 3001, Trans instruments, Singapore PTE, LTD) using (30-ml) sample placed in (50-ml) capacity beakers (Jampani et al. 2012). All measurements were repeated three times.

\section{Percent transmittance measurement}

This test was conducted in order to determine the clarity of prepared NEs. Transmittance of each NE system was determined using UV/Vis spectrophotometer (UV-6100 PC, EMC lab, Germany) at $650 \mathrm{~nm}$ keeping deionized 
water as a blank. Measurements were made in triplicate (Nasr et al. 2016).

\section{Determination of surface tension}

Surface tension in all prepared CC NEs was determined by using tensiometer instrument (Sigma 703D, U.K.) according to Du Noüy ring method. In this method, about $50 \mathrm{ml}$ capacity beaker containing the NE sample to be analyzed and a platinum ring that is fixed to a sensitive force are measuring device. The container is able to move freely in a controller manner while ring position is constant. The initial position of a ring is drowning in the surface of liquid. It slowly lowered and leads to a record of the exerting force on the ring. When the surface of liquid move downward, due to surface tension, some of liquid adheres to the ring. Weight of adhered liquid to the ring is proportionate to surface tension and recorded by force measuring accessory (Mandal and Bera 2012).

\section{Measurement of refractive index}

Refractive index for each prepared CC NE formula was measured using Abbe refractometer (Boeco, Germany) by placing one drop of $\mathrm{NE}$ on the glass slide and records a measurement. The measurements were made in triplicate at $25 \pm 1{ }^{\circ} \mathrm{C}$ (Wais et al. 2012).

\section{In vitro drug dissolution study}

The quantitative in vitro release test was performed in $900 \mathrm{ml}$ of $0.1 \mathrm{~N} \mathrm{HCl}$ solutions (pH 1.2) using USP dissolution apparatus type II (paddle method) (DIS 6000, Copley scientific, U.K.) at $50 \mathrm{rpm}$ and $37 \pm 0.5^{\circ} \mathrm{C}$ using dialysis bag technique (Molecular cut off 12000 Dalton "Da"). About 4$5 \mathrm{ml}(5 \mathrm{~g})$ of NE formulation equivalent to $8 \mathrm{mg}$ of CC was placed in dialysis bag. Samples $(10 \mathrm{ml})$ were withdrawn at a regular time interval $(5,10,15,20,25,30,35,40,45,50,55$ and $60 \mathrm{~min}$ ) and an aliquot amount of 0.1 normal " $\mathrm{N}$ " $\mathrm{HCl}$ was replaced to maintain sink condition. The release of CC from NE formulation was compared with marketed tablets (Atacand $8 \mathrm{mg}$ ) and plain CC powder (Vuddisa et al. 2014).

\section{In vitro drug release kinetics study}

To study the kinetics and mechanism of CC release from various $\mathrm{NE}$ formulations, data obtained from in vitro drug release study was plotted in various mathematical models including: zero order, first order, Higuchi's and Korsmeyer's models (Krishna et al. 2013).

\section{Selection of optimum candesartan cilexetil nanoemulsion formula}

The optimum formula for CC NE was selected according to the following parameters: droplet size distribution, PDI, zeta potential viscosity, electroconductivity, $\mathrm{pH}$, transmittance percentage, surface tension, refractive index, low Smix concentration and in vitro drug dissolution result.

\section{Morphology examination of optimum candesartan cilexetil nanoemulsion formula}

The surface topography characteristics of the selected NE formula were investigated by using scanning probe microscope instrument (SPM-AA3000, Angstrom Advanced Inc, USA). The instrument measurement basically relied on electrical charges pass from the surface of an object to the point of the microscope without there being any contact. The current varies strongly with distance. The movement of the probe of the microscope is controlled by a specific current value in order to follow exactly the surface of the sample (Thassu et al. 2007).

\section{Stability study}

To evaluate the physical stability of the optimum formulated $\mathrm{NE}$ for $\mathrm{CC}$, it was stored at $40{ }^{\circ} \mathrm{C}$ and $75 \%$ relative humidity (RH) in an oven (Memmert oven, W. Germany) for three months. The NE parameters including: droplet size distribution, PDI, zeta potential, $\mathrm{pH}$, viscosity, transmittance percent, electroconductivity, refractive index, surface tension and in vitro drug dissolution were determined after one and three months storage. In addition, expiration date was determined also by using Arrhenius plot (Yadav et al. 2014; Elnaggar et al. 2009).

\section{Statistical analysis}

The statistical significance of differences was determined by utilizing one-way-analysis of variance (ANOVA) test. The $p$ value $<0.05$ was considered to be significant.

\section{Results and discussion}

\section{Solubility studies}

Amongst the various oils that were screened (Fig. 1), cinnamon oil showed the best results and could solubilize the target dose of CC $(8 \mathrm{mg})$ at the relatively small amount. From various surfactants tested (Fig. 2) a mixture of tween 80 and poloxamer was shown a high ability to dissolve CC and was selected for the study. In addition to that, this mixture of surfactants has high HLB value corresponding to tween 80 , poloxamer 188 , poloxamer 407 and poloxamer 338 which are 15, 29, 20 and 27, respectively (Rowe et al. 2006; Raavi et al. 2014; Al-Nima et al. 2014).

From all co-surfactants tested (Fig. 3), transcutol HP with HLB value of 4.3 (Rao et al. 2015) demonstrates a good capability to dissolve a large quantity $\mathrm{CC}$ and was selected for this research. The final HLB of the system was regulated above 10 in order to form efficient $\mathrm{o} / \mathrm{w}$ NE (Jain et al. 2013). Furthermore, all surfactants and co-surfactant were selected to be non-ionic in nature since, they are non-toxic and non-irritant relative to ionic one and fall into generally regarded as safe (GRAS) class (Strickley 2004; Yasser et al. 2013). 


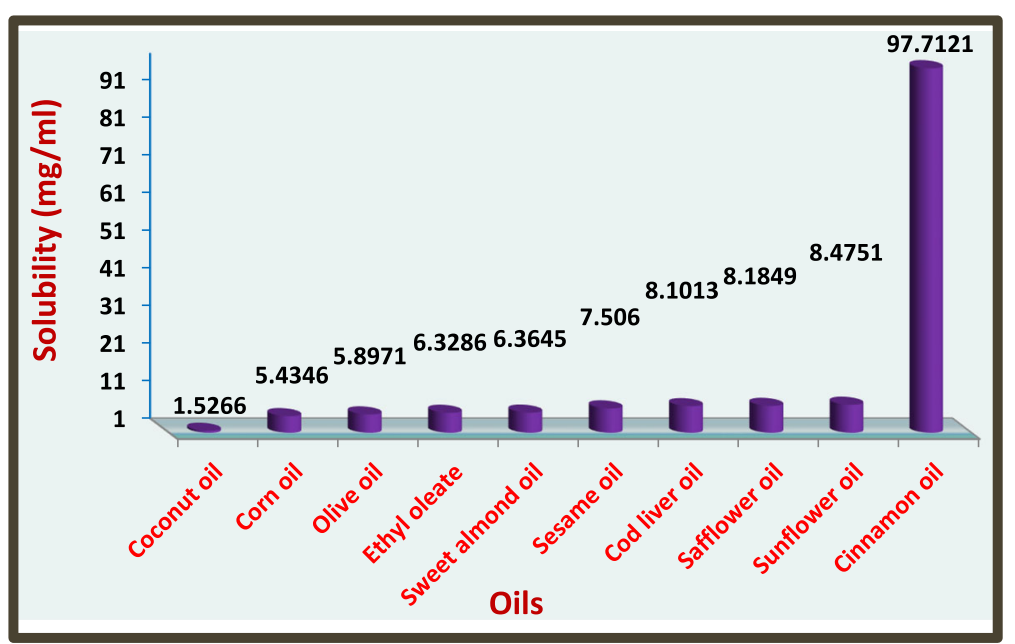

Fig. 1 Solubility study results of candesartan cilexetil in different oils

\section{Construction of pseudo-ternary phase diagrams}

Pseudo-ternary phase diagram results are shown in (Fig. 4). System (C) containing tween 80 with poloxamer 338 producing a small region of NE compared to other systems and less nanoemulsification properties. However, the pseudo-ternary phase diagrams of system (B) containing tween 80 with poloxamer 407 mixture has the best nanoemulsification properties compared to other two mixtures.

It was clear that, for all poloxamer types examined, an increase in HLB value resulted in an increase of
NE area, since increase HLB number leads to an increase in hydrophilicity of the system, so better aqueous miscibility outcome. Within the shaded areas, NEs were formed with only gentle magnetic stirring. This is possible as tween 80 with poloxamer mixture strongly localized on the surface of the NE droplets reducing the interfacial free energy and providing a mechanical barrier to coalescence resulting in a spontaneous dispersion (Souto et al. 2011). All prepared CC NEs were easily miscible with water without

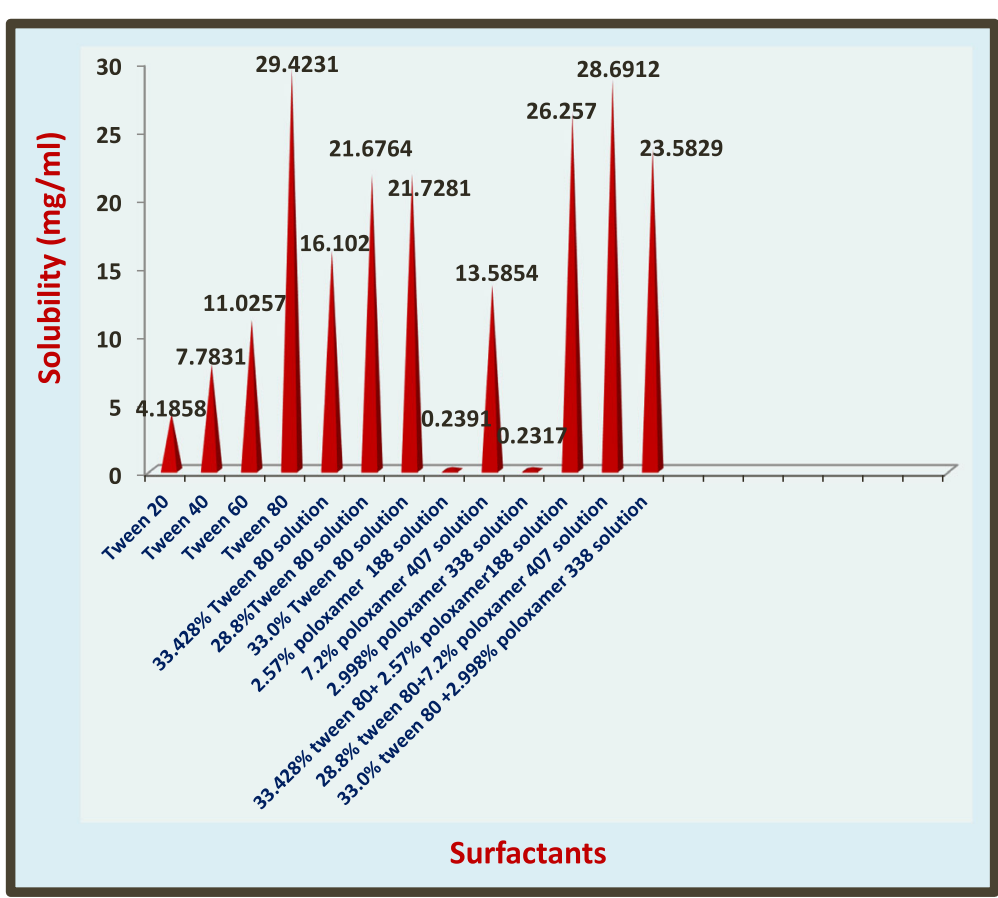

Fig. 2 Solubility study results of candesartan cilexetil in different surfactants 


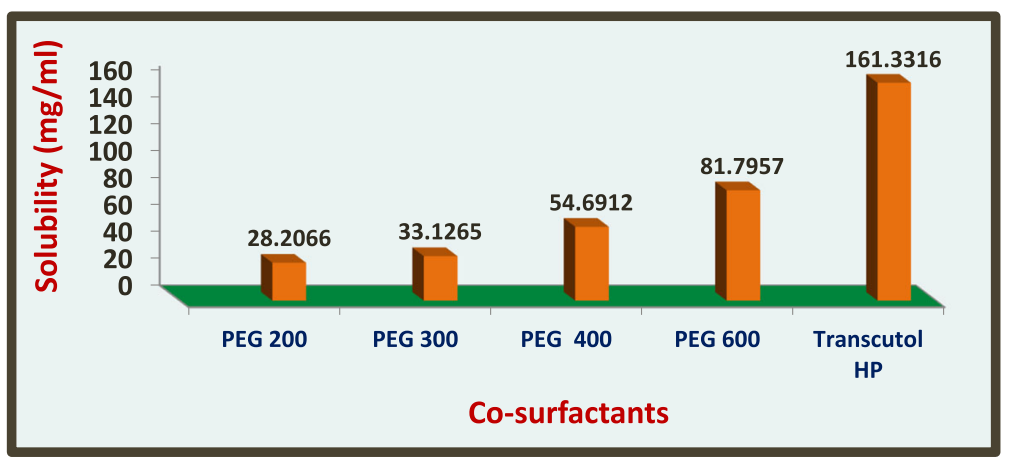

Fig. 3 Solubility study results of candesartan cilexetil in different co-surfactants

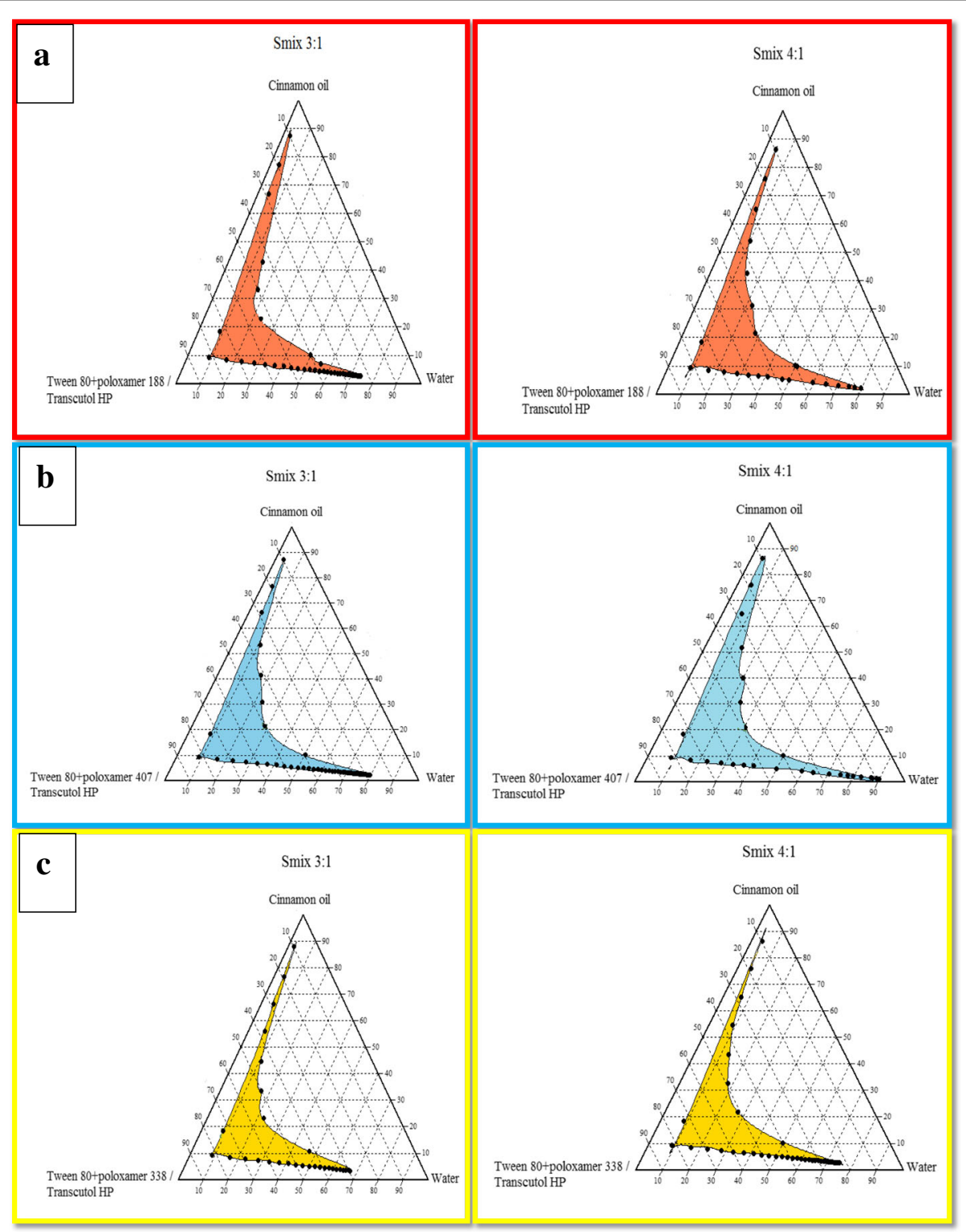

Fig. 4 Pseudo-ternary phase diagrams showing the o/w nanoemulsion (shaded area) regions of cinnamon oil (oil), tween 80 with different poloxamer mixture (surfactant), transcutol HP (co-surfactant) and water in 3:1 and 4:1 Smix ratios at $25^{\circ} \mathrm{C}$ using: a Poloxamer 188, b Poloxamer 407 and c) Poloxamer 338 
going turbid or separate. This confirms that all NE formulations prepared were of $\mathrm{o} / \mathrm{w}$ type.

\section{Preparation of candesartan cilexetil nanoemulsions}

Eight clear, transparent, easily flowable and low-viscous mixtures that formed within few seconds were resulted from each Smix ratio used and with each poloxamer without phase separation (Tables 1 and 2). In all NE formulations, concentrations of oil, surfactant and cosurfactant were simultaneously changed resulted in the formation of solubilized drug inside a cinnamon oil core surrounded by a layer of surfactant mixture and cosurfactant that protect the drug from the surrounding aqueous phase (Fig. 5). All of NE formulations were chosen based on the lowest oil and Smix concentrations.

\section{Evaluations of prepared candesartan cilexetil nanoemulsions}

Nanodispersion stability studies

All eight NE formulations survived dispersion stability tests successfully without phase separation or drug precipitation and they were selected for further studies.

\section{Determination of droplet size distribution and poldispersity index}

The NE properties, that is, size and PDI; have been shown to be closely related to the relative concentrations of cinnamon oil and tween 80 with poloxamer mixture used. All prepared NE formulations were in the defined nanosize diameter (Table 3). The variation in droplet size may be attributed to variation in the penetration of cinnamon oil molecules into the hydrophobic region of tween 80 with poloxamer mixture alkyl chain that affects film flexibility, surface curvature and consequently globule size (Poornima and Krishna 2016; Dhawan et al. 2014).

It is worth noting that poloxamer 407 has shown the best control of NE droplet size compared to poloxamer 188 and poloxamer 338 owing to their intermediate MWT and hydrophilicity relative to both. In any combination of tween 80 and poloxamer, the NE droplet size was not significantly different $(p>0.05)$.
However, mean globule size increased with decreasing Smix concentration. This phenomenon could be attributed to the higher concentration of the Smix required to produce fine and stable NE due to the fact that smaller globule size, greater is the surface area and hence, the greater amount of Smix required to stabilize the cinnamon oil globules (Eid et al. 2013). Results obtained for PDI values of formulations were found to be less than 0.5 which indicate the uniformity of droplet size distribution dispersed cinnamon oil globules within the formulation and affirm their homogeneity (Mahmoud et al. 2013).

\section{Zeta potential measurement}

From the stability point of view, zeta potential, $\zeta$ is an important parameter that reflects the stability of the system. The zeta potential is defined as the diversity in potential between the surface of the tightly bound region and the electro neutral region of the solution reflects the surface charge of particles with an associated counter ion. Zeta potential signifies repulsion force degree between adjacent charged particles in nanodispersion (Honary and Zahir 2013; Kulshreshtha et al. 2010).

It was found, that all of the prepared NE formulations have a high negative value of zeta potential charge above $(-30 \mathrm{mV})$ as demonstrated in (Table 3), which indicates that NE formulations were stable. The existence of high negative charge on the prepared NE formulations could be due to the presence of anionic groups of fatty acids in the cinnamon oil, tween 80 , glycol part of poloxamer and alcohol moiety of transcutol HP (Ahmad et al. 2014).

Another point to be added that further potentiate the NE stability is the polymeric and bulky flexible structure of poloxamer which can stabilize the nanosystem by creating spatial exclusion, cover the surface of nanodroplets efficiently and avoid the formation of van der Waals forces between the nanodroplets (Pratiwi et al. 2016; Seo et al. 2015).

\section{Viscosity determination, filter paper test, dye miscibility test and electroconductivity measurement}

Viscosity of formulations was brought to an optimum by addition of poloxamer, since it acts as a stabilizer and

Table 1 Composition (\%w/w) of different candesartan cilexetil nanoemulsions

\begin{tabular}{lllllll}
\hline F-code & Smix ratio & Oil:Smix & Cinnamon oil \% & Smix used & Smix \% & Water \% \\
\hline NE-1 & $3: 1$ & $1: 9$ & 4.00 & Tween 80 + P* 188: transcutol HP & 36.000 & 60.000 \\
NE-2 & $4: 1$ & $1: 9$ & 4.00 & Tween 80 + P 188: transcutol HP & 36.000 & 60.000 \\
NE-3 & $3: 1$ & $1: 9$ & 4.00 & Tween 80 + P 407: transcutol HP & 36.000 & 60.000 \\
NE-4 & $3: 1$ & $1: 9$ & 3.03 & Tween 80 + P 407: transcutol HP & 27.272 & 69.696 \\
NE-5 & $4: 1$ & $1: 9$ & 4.00 & Tween 80 + P 407: transcutol HP & 36.000 & 60.000 \\
NE-6 & $4: 1$ & $1: 9$ & 3.03 & Tween 80 + P 407: transcutol HP & 27.272 & 69.696 \\
NE-7 & $3: 1$ & $1: 9$ & 4.00 & Tween 80 + P 338: transcutol HP & 36.000 & 60.000 \\
NE-8 & $4: 1$ & $1: 9$ & 4.00 & Tween 80 + P 338: transcutol HP & 36.000 & 60.000 \\
\hline
\end{tabular}

*Where $(\mathrm{P})$ denotes poloxamer 
Table 2 Composition (\%w/w) of Smix of different candesartan cilexetil nanoemulsions

\begin{tabular}{lllll}
\hline F-code & Smix used & Tween 80\% & Poloxamer \% & Transcutol HP \% \\
\hline NE-1 & Tween 80 + P*188: transcutol HP & 25.0722 & 1.9278 & 9.0000 \\
NE-2 & Tween 80 + P 188: transcutol HP & 26.7420 & 2.0560 & 7.2000 \\
NE-3 & Tween 80 + P 407: transcutol HP & 21.6000 & 5.4000 & 9.0000 \\
NE-4 & Tween 80 + P 407: transcutol HP & 16.3632 & 4.0908 & 6.8180 \\
NE-5 & Tween 80 + P 407: transcutol HP & 23.0400 & 5.7600 & 7.2000 \\
NE-6 & Tween 80 + P 407: transcutol HP & 17.4540 & 4.3620 & 5.4544 \\
NE-7 & Tween 80 + P 338: transcutol HP & 24.7500 & 2.2480 & 9.0000 \\
NE-8 & Tween 80 + P 338: transcutol HP & 26.4000 & 2.3980 & 7.2000 \\
\hline
\end{tabular}

*Where $(\mathrm{P})$ denotes poloxamer

viscosity regulator (Sainsbury et al. 2014). Also, the use of transcutol HP having low intrinsic viscosity further control viscosity to a suitable low value (Vishnu et al. 2015). The Newtonian definition of viscosity relates the rate of flow to the applied stress and is expressed in Eq. 4.

$$
\eta=\frac{\tau}{D}
$$

Where: rate of flow is signified by (D) and applied stress is denoted by ( $\tau$ ) (Schuh et al. 2014). Via drawing shear rate versus shear stress, It was found that all NEs viscosity obtained were of Newtonian flow behavior (Fig. 6). Moreover, with an increase in surfactant mixture concentration using cinnamon oil, the viscosity of $\mathrm{NE}$ increased correspondingly (Table 4). This is because an increase in surfactant mixture concentration causes water molecules to get trapped in cross-linking surfactants chains and resulted in increased viscosity of the NE (Mishra et al. 2014).

It could be concluded from viscosity values results that the investigated $\mathrm{CC} \mathrm{NE}$ formulations were all of o/w type. There is a significant difference in viscosity $(p<0.05)$ between NE formulations prepared with different poloxamer types and the same concentrations (weight by weight

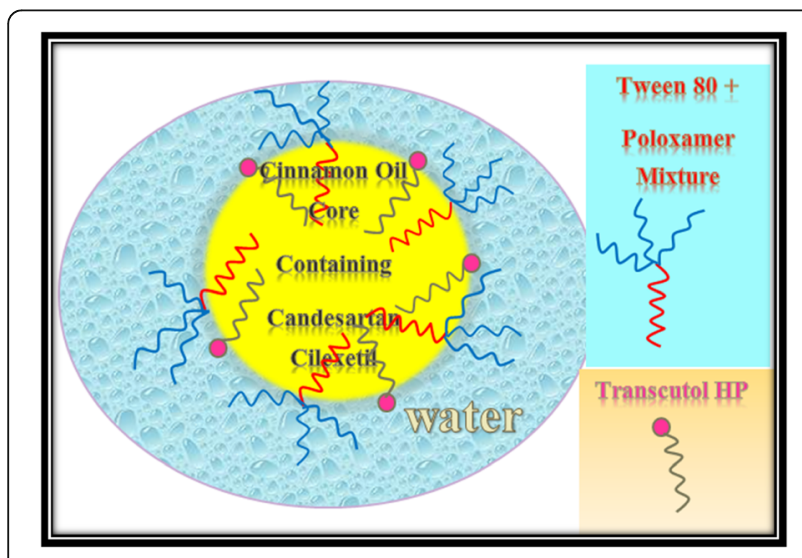

Fig. 5 Schematic representation of candesartan cilexetil nanoemulsion droplet percent "w/w \%") of oil, surfactant mixture and cosurfactant. Over and above, formulations prepared with poloxamer 188 have the least viscosity values and poloxamer 338 containing formulations have the highest values.

Lastly, poloxamer 407 prepared formulations showed intermediate results of viscosity. The plausible rationale might be the difference in MWT of poloxamers used, where in poloxamer 188 has MWT range between (7680 g/mole) and (9510 g/mole), poloxamer $407 \mathrm{MWT}$ range of (9840-14600 g/mole) and poloxamer 338 has MWT range from $(12700 \mathrm{~g} / \mathrm{mole})$ to $(17400 \mathrm{~g} / \mathrm{mole})$ (Rowe et al. 2006).

Regarding filter paper test, results indicate rapid spreadability of all CC NEs over filter papers due to aqueous nature of continuous phase. Also, after adding methyl orange dye, it was noted that the dye was homogenously miscible with all CC NE formulations (Fig. 7). The results of electroconductivity test indicated that the investigated NE formulations of $\mathrm{CC}$ were all of o/w type, since all resulted values were above 10 micro simenens/ centimeter " $\mu \mathrm{s} / \mathrm{cm}$ " (Table 5) (Hassan 2015).

Above $50 \%$ water, a dramatic increase in conductivity was observed; furthermore, a sharp increase in conductivity was found at $69.696 \%$ water $(192.3666 \pm 0.7571 \mu \mathrm{s} /$ $\mathrm{cm})$. Increase water content leads to a linear increase in conductivity due to enhancing the movement of free ions in NE (Talegaonkar et al. 2011). On the other hand,

Table 3 Mean droplet size distribution, polydispersity index and zeta potential of candesartan cilexetil nanoemulsions

\begin{tabular}{llll}
\hline F-code & Droplet size $(\mathrm{nm})$ & PDI & Zeta potential $(\mathrm{mV})$ \\
\hline $\mathrm{NE}-1$ & 24.2 & 0.400 & -105.88 \\
$\mathrm{NE}-2$ & 23.7 & 0.259 & -138.64 \\
$\mathrm{NE}-3$ & 20.8 & 0.225 & -126.45 \\
$\mathrm{NE}-4$ & 22.1 & 0.229 & -120.82 \\
$\mathrm{NE}-5$ & 20.7 & 0.223 & -131.43 \\
$\mathrm{NE}-6$ & 24.2 & 0.241 & -129.52 \\
$\mathrm{NE}-7$ & 39.7 & 0.317 & -90.50 \\
$\mathrm{NE}-8$ & 39.3 & 0.313 & -95.07 \\
\hline
\end{tabular}




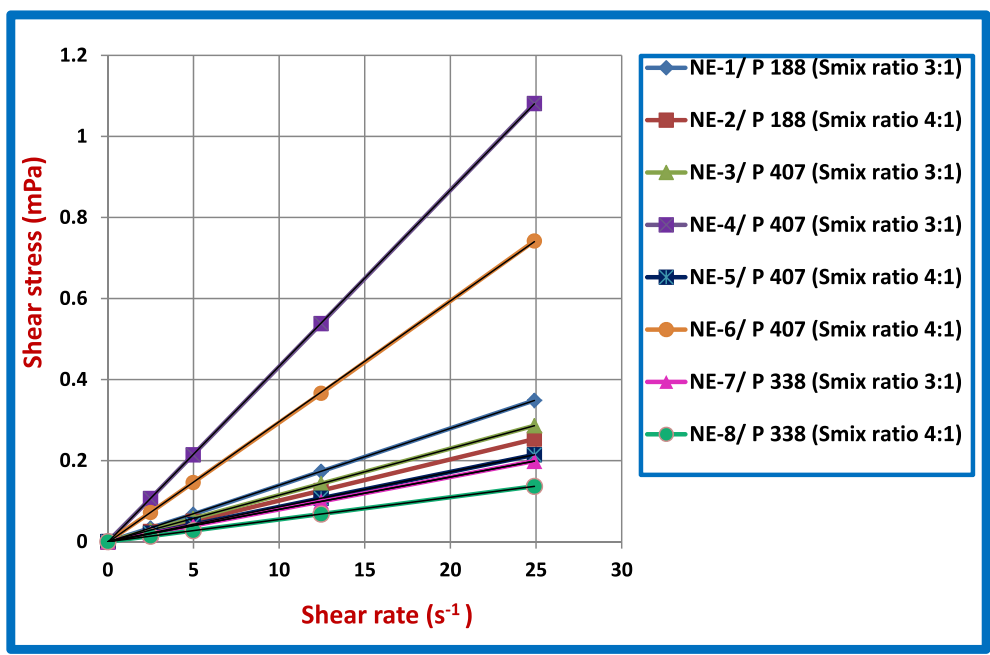

Fig. 6 Rheogram of candesartan cilexetil nanoemulsions (NE-1, NE-2, NE-3, NE-4, NE-5, NE-6, NE-7 and NE-8)

the least electroconductivity value was seen in NE-7 $(135.3666 \pm 0.4160 \mu \mathrm{s} / \mathrm{cm})$ due to less water content. It was found from the results, that there was nonsignificant difference $(p>0.05)$ in electrical conductivity between NEs. Furthermore, poloxamer-stabilized NE had higher conductivity due to the viscosity-thinning effect of poloxamer, and hence higher electrolyte shift (Ofokansi et al. 2013).

\section{Measurement of $\mathrm{pH}$}

Results of $\mathrm{pH}$ determination (Table 6) indicating that increase cinnamon oil content leads to an increase in $\mathrm{pH}$. This is due to increase trapping of the acidic drug inside inner oily core and prevents its leakage into aqueous continuous phase. There is no significant difference $(p>0.05)$ in $\mathrm{pH}$ between all $\mathrm{NE}$ formulations.

\section{Percent transmittance measurement}

Values of percentage transmittance closer to $100 \%$ indicated that all of the optimized NEs were clear, transparent and transmit light easily (Table 6).
Formulation (NE-5) was found to have the highest transmittance percentage value $(99.8835 \% \pm 0.5859 \%)$ and (NE-7) was found to have the least transmittance percentage value $(97.4333 \% \pm 0.5033 \%)$. Their transparency is attributed to their small size that is less than $25 \%$ of the wave length of light (Sarkar and Hardenia 2011). There is no significant difference in transmittance between all NE formulations $(p>0.05)$.

\section{Determination of surface tension}

Surface tension is a function of temperature and composition of both phases. Surface energy (ES) of a NE with droplet diameter (d) is best described by Eq. 5 .

$$
E_{(s)}=N \sigma \pi d^{2}
$$

Where: $\mathrm{N}$ is the number of droplets and $\sigma$ is the interfacial tension between the two phases. The energy requirement for formation of $\mathrm{NE}$ can be reduced if surface tension is reduced and this is could be achieved by the addition of surfactant. In nanoemulsification,

Table 4 Viscosity results of candesartan cilexetil nanoemulsions

\begin{tabular}{|c|c|c|c|c|}
\hline \multirow{2}{*}{$\begin{array}{l}\text { F- } \\
\text { code }\end{array}$} & \multicolumn{4}{|l|}{ Viscosity (mPa.s) } \\
\hline & $6 \mathrm{rpm}$ & $12 \mathrm{rpm}$ & $30 \mathrm{rpm}$ & $60 \mathrm{rpm}$ \\
\hline $\mathrm{NE}-1$ & $73.9000 \pm 1.0440$ & $73.7666 \pm 6.3129$ & $71.7333 \pm 1.8009$ & $71.4333 \pm 0.7234$ \\
\hline $\mathrm{NE}-2$ & $99.5333 \pm 1.2503$ & $98.7333 \pm 0.0577$ & $98.6333 \pm 4.4286$ & $98.3666 \pm 6.5597$ \\
\hline$N E-3$ & $87.3666 \pm 0.4509$ & $87.2666 \pm 1.7953$ & $87.0333 \pm 1.0016$ & $87.0000 \pm 2.9715$ \\
\hline$N E-4$ & $23.3666 \pm 0.3511$ & $23.2333 \pm 0.3511$ & $23.1333 \pm 1.0503$ & $23.0333 \pm 0.1527$ \\
\hline$N E-5$ & $117.9000 \pm 1.4730$ & $117.5000 \pm 2.4979$ & $116.1666 \pm 0.3511$ & $116.1333 \pm 1.0408$ \\
\hline NE-6 & $34.5666 \pm 0.4163$ & $34.1333 \pm 1.3650$ & $34.0000 \pm 0.9165$ & $33.5666 \pm 0.7094$ \\
\hline $\mathrm{NE}-7$ & $125.9666 \pm 0.7767$ & $125.8000 \pm 0.6570$ & $125.5333 \pm 5.1617$ & $125.2000 \pm 10.0861$ \\
\hline $\mathrm{NE}-8$ & $182.9000 \pm 9.7524$ & $182.5000 \pm 8.5737$ & $182.4000 \pm 8.5982$ & $182.3333 \pm 2.4501$ \\
\hline
\end{tabular}




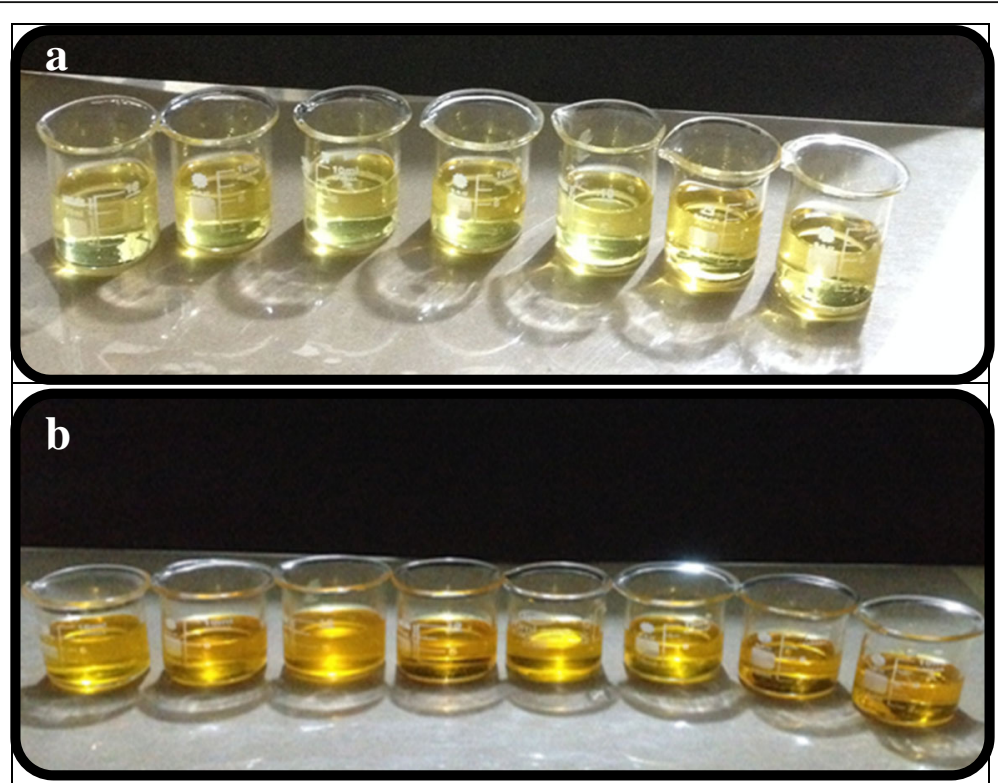

Fig. 7 Results of dye test; upper picture (a) representing candesartan cilexetil nanoemulsion formulations before adding methyl orange dye (water soluble) and the lower picture (b) showing the homogenous miscibility of the dye with nanoemulsions

shear forces help create more surface and hence smaller droplet size NE, whereas the surface tension opposes the formation of more surface (Gupta and Kompella 2006; Desai et al. 2015).

Anywise, All NE formulations were successful in reducing water surface tension value (72.6 milli newton per meter " $\mathrm{mN} / \mathrm{m}$ ") nearly to the half and providing a superior wettability and spreadability for formulations (Agubata et al. 2014; Díaz-Blancas et al. 2016). It was found that increasing the concentration of surfactant mixture (Table 6) leads to a decrease in surface tension since increasing concentration of surfactant mixture will increase surface activity at the air/water interface (Zhang and Lam 2006). It was concluded from all data presented, that there was no significant difference between formulations in surface tension results $(p>0.05)$.

\section{Measurement of refractive index}

Refractive index (RI), n, of a medium is defined as the ratio of speed, c, of a wave such as light or sound in a reference medium to the phase speed, vp, of the wave in the medium and can be expressed by Eq. 6 (Bhatt and Madhav 2011).

$$
\mathrm{n}=\mathrm{c} / \mathrm{vp}
$$

The results tabulated in (Table 7) indicate that RI values of all developed NE systems were found to be close to that of the water (1.334) and they were increased with an increase in concentration ( $\mathrm{w} / \mathrm{w} \%)$ of cinnamon oil and a decrease in water content percent. It could be concluded that the NE formulations were not only transparent systems transmit the light easily but also they were isotropic in nature (Talegaonkar et al. 2011). There was no

Table 5 Electroconductivity, filter paper test and dye test results of candesartan cilexetil nanoemulsions

\begin{tabular}{|c|c|c|c|c|c|}
\hline F-code & Water content (\% w/w) & Electrical conductivity $(\mu \mathrm{s} / \mathrm{cm})$ & Filter paper test & Dye test & Type of nanoemulsion \\
\hline$\overline{\mathrm{NE}-1}$ & 60.000 & $227.3333 \pm 2.0810$ & Highly spreadable & Miscible & $\mathrm{o} / \mathrm{w}$ \\
\hline $\mathrm{NE}-2$ & 60.000 & $237.3333 \pm 5.5070$ & Highly spreadable & Miscible & $\mathrm{o} / \mathrm{w}$ \\
\hline NE-3 & 60.000 & $158.6333 \pm 0.3511$ & Highly spreadable & Miscible & $\mathrm{o} / \mathrm{w}$ \\
\hline$N E-4$ & 69.696 & $181.0666 \pm 0.2080$ & Highly spreadable & Miscible & $\mathrm{o} / \mathrm{w}$ \\
\hline$N E-5$ & 60.000 & $166.9000 \pm 0.1000$ & Highly spreadable & Miscible & $\mathrm{o} / \mathrm{w}$ \\
\hline NE-6 & 69.696 & $192.3666 \pm 0.7571$ & Highly spreadable & Miscible & $\mathrm{o} / \mathrm{w}$ \\
\hline $\mathrm{NE}-7$ & 60.000 & $135.3666 \pm 0.4160$ & Highly spreadable & Miscible & $\mathrm{o} / \mathrm{w}$ \\
\hline $\mathrm{NE}-8$ & 60.000 & $153.6333 \pm 0.3210$ & Highly spreadable & Miscible & $\mathrm{o} / \mathrm{w}$ \\
\hline
\end{tabular}


Table 6 Results of $\mathrm{pH}$, transmittance percent and surface tension determination of candesartan cilexetil nanoemulsions

\begin{tabular}{llll}
\hline F-code & $\mathrm{pH}$ & Transmittance $\%$ & Surface tension $(\mathrm{mN} / \mathrm{m})$ \\
\hline $\mathrm{NE}-1$ & $5.1033 \pm 0.0890$ & $98.3333 \pm 0.2081$ & 45.33 \\
$\mathrm{NE}-2$ & $5.1466 \pm 0.0500$ & $98.6333 \pm 0.0577$ & 45.12 \\
$\mathrm{NE}-3$ & $5.1500 \pm 0.2780$ & $99.8666 \pm 0.2309$ & 45.27 \\
$\mathrm{NE}-4$ & $5.0966 \pm 0.2630$ & $99.8433 \pm 0.2081$ & 45.31 \\
$\mathrm{NE}-5$ & $5.1733 \pm 0.0940$ & $99.8835 \pm 0.5859$ & 45.22 \\
$\mathrm{NE}-6$ & $5.1366 \pm 0.1070$ & $99.8660 \pm 0.3000$ & 45.29 \\
$\mathrm{NE}-7$ & $4.8366 \pm 0.3780$ & $97.4333 \pm 0.5033$ & 45.36 \\
$\mathrm{NE}-8$ & $4.9266 \pm 0.0350$ & $97.7000 \pm 0.1000$ & 45.27 \\
\hline
\end{tabular}

significant difference in RI value among all prepared NE systems $(p>0.05)$.

\section{In vitro drug dissolution study}

Results of cumulative CC released percentage from all eight NE formulations are shown in (Fig. 8). All prepared NEs for CC showed the highest release in less than an hour. This could be attributed to the fact that the quantitative release of CC from NE formulations is droplet size dependent. This proposed that larger interfacial area exists in NE with small drops, promotes rapid drug release (Sharma et al. 2012).

Release of CC from NE formulations was faster at Smix concentration percent lower than $36 \%$ and this is may be attributed to the fact that the high Smix concentration may lead to sequestration of the drug into the surfactant micelles or emulsified cinnamon oil droplets and delay the release of the drug via the dialysis bag (Sainsbury et al. 2014).

On the basis of in vitro drug release study, NE-4 formula (Fig. 9) was found to be better than the other NE formulations due to the high thermodynamic activity of drug and it was selected as the optimized formulation.

Table 7 Refractive index results of candesartan cilexetil nanoemulsions

\begin{tabular}{ll}
\hline F-code & Refractive index (RI) \\
\hline NE-1 & $1.3931 \pm 0.0013$ \\
$N E-2$ & $1.3950 \pm 0.0030$ \\
$N E-3$ & $1.3942 \pm 0.0002$ \\
$N E-4$ & $1.3793 \pm 0.0014$ \\
$N E-5$ & $1.3951 \pm 0.0004$ \\
$N E-6$ & $1.3817 \pm 0.0001$ \\
$N E-7$ & $1.3941 \pm 0.0003$ \\
$N E-8$ & $1.3947 \pm 0.0007$ \\
\hline
\end{tabular}

The results clearly affirm that the percentage of CC dissolved from NE-4 reached $99.6652 \%$ within $30 \mathrm{~min}$, while about $18.3250 \%$ of plain CC powder was dissolved after $30 \mathrm{~min}$ and marketed tablet (Atacand ${ }^{\circ}$ $8 \mathrm{mg}$ ) reached (31.9099\%) cumulative CC released after $30 \mathrm{~min}$.

\section{In vitro drug release kinetics study}

To clarify the mode and mechanism of $\mathrm{CC}$ release from $\mathrm{NE}$ formulations, the in vitro release data was transformed into various graphical forms and translated according to distinct kinetic models. The kinetics of the dissolution data were well fitted to zero-order, firstorder, Higuchi model and $60 \%$ of release data were fitted to Korsmeyer-Peppas equation (Vishnu et al. 2015; Bruschi 2015).

$$
\begin{aligned}
& \mathrm{Mt}=\mathrm{M}_{0}+\mathrm{k}_{0} \mathrm{t} \\
& \ln \mathrm{Mt}=\ln _{0}+\mathrm{k}_{1} \mathrm{t} \\
& \mathrm{Mt}=\mathrm{M}_{0}+\mathrm{k}_{\mathrm{H} \cdot t_{1 / 2}} \\
& \frac{\mathrm{Mt}}{M_{\infty}}=\mathrm{k} \times t_{n}
\end{aligned}
$$

Where: Mt is the cumulative amount of drug released at any time (t), $\mathrm{M}_{0}$ is the dose of the drug loaded in the delivery system, $k_{0}, k_{1}, k_{H}$ and $k$ are rate constants for zero-order, first-order, Higuchi and Korsmeyer models; respectively, $M_{t} / M_{\infty}$ is the fraction of drug released at time $(t)$ and $n$ is release exponent. The highest correlation coefficient $\left(R^{2}\right)$ is used for selecting the order of drug release (zero, first or Higuchi). Further to add, the highest release exponent (n) obtained from applying (Eq. 10) determines the release mechanism (Fickian or non-Fickian) (Miastkowska et al. 2016).

Moreover, If $(\mathrm{n})$ value is within the range of $(0.43-$ $0.50)$, then release follows Fickian diffusion, while (n) value greater than (0.5) corresponding to non-Fickian transport mechanism and it is further divided into three ranges as follows: $0.50<\mathrm{n}<0.89$ for anomalous release, $0.89<\mathrm{n}<1.00$ for case II transport and $\mathrm{n}>1.00$ for super case II transport (Felton 2013). In the same token, the best fit with the highest $\left(R^{2}\right)$ value was found to be shown by zero order release fashion for all NE formulations (Table 8). The values of ( $\mathrm{n}$ ) for all of these formulations were above (1), indicating non-Fickian supercase-II transport diffusion release mechanism (Table 8).

One interpretation of this diffusion-based mechanism is that the cinnamon oil will create a (filter) or a (membrane-like barrier) against the hydrophilic sheath of NE. As a result, the CC molecules leakage from the NE followed a linear release behavior as long as this oily barrier is intact. This zero-order release process can be 


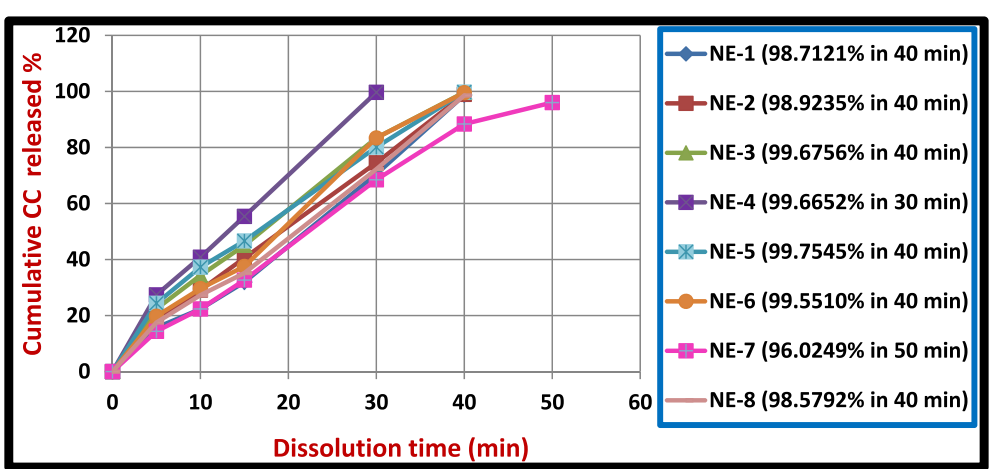

Fig. 8 A comparative dissolution profile of candesartan cilexetil nanoemulsions (NE- 1, NE-2, NE-3, NE-4, NE-5, NE-6, NE-7 and NE-8 in $900 \mathrm{ml}$ of $0.1 \mathrm{~N} \mathrm{HCl}$ dissolution medium ( $\mathrm{pH} \mathrm{1.2)} \mathrm{with} 0.5 \%$ tween 20 at $37^{\circ} \mathrm{C}$

described as a constant regime, also called (steady state diffusion) (Kamalakkannan et al. 2013). Finally, data are now emerging showed that release profiles of CC from all NEs comply with united state pharmacopeia (USP) guidelines with an amount of drug released nearly $100 \%$.

\section{Selection of candesartan cilexetil optimum nanoemulsion formula}

Based on optimum droplet size $(22.1 \mathrm{~nm})$, minimum PDI (0.229), high zeta potential $(-120.82 \mathrm{mV})$, optimum $\mathrm{pH}$ $(5.0966 \pm 0.263)$, lower viscosity $(23.0333 \pm 0.1527 \mathrm{mPa} . \mathrm{s})$, high transmittance \% $(99.8433 \% \pm 0.2081 \%)$, high electroconductivity value $(181.0666 \pm 0.208 \mu \mathrm{s} / \mathrm{cm})$, lower RI $(1.3793 \pm 0.00145)$, low surface tension $(45.31 \mathrm{mN} / \mathrm{m})$, overall lower surfactant and co-surfactant concentrations $(27.272 \% \mathrm{w} / \mathrm{w})$ and highest release $(99.6652 \% \pm 0.3226 \%)$ compared to other NE formulations, (NE-4) was selected as an optimum NE formulation for $\mathrm{CC}$ which consisted of $3.030 \% \mathrm{w} / \mathrm{w}$ of cinnamon oil, $16.3632 \% \mathrm{w} / \mathrm{w}$ of tween 80 , $4.0908 \% \mathrm{w} / \mathrm{w}$ of poloxamer $407,6.818 \% \mathrm{w} / \mathrm{w}$ of transcutol $\mathrm{HP}$ and $69.696 \% \mathrm{w} / \mathrm{w}$ of deionized water (Fig. 10).
Solubility study in (NE-4) formula revealed that solubility of $\mathrm{CC}$ was found to be highly increased in NE optimum formula and was found to be (223.2472 \pm $2.3117 \mathrm{mg} / \mathrm{ml}$ ). Increase the solubility of CC will keep this hydrophobic drug in solution and this speculate an enhancement in absorption of CC from the gastro intestinal tract (GIT) which are advantageous in reducing the dose of drug while concurrently increasing its bioavailability and changing the drug up take and disposition mechanisms via altering enterocyte-based transport and enhancing drug delivery to the systemic circulation via intestinal lymphatic system.

\section{Morphology examination of optimum candesartan cilexetil nanoemulsion formula}

Scanning probe microscopic (SPM) image of optimum CC cinnamon oil NE (NE-4) shown in (Fig. 11) depicted a group of spheres have minimum interparticulate contact and generally optimal properties. In addition, SPM analysis also confirmed the nanometric droplet diameter of formulated $\mathrm{NE}$ with an average droplet size of $(73.43 \mathrm{~nm})$. The average droplet size result from the SPM instrument differs from that obtained via laser

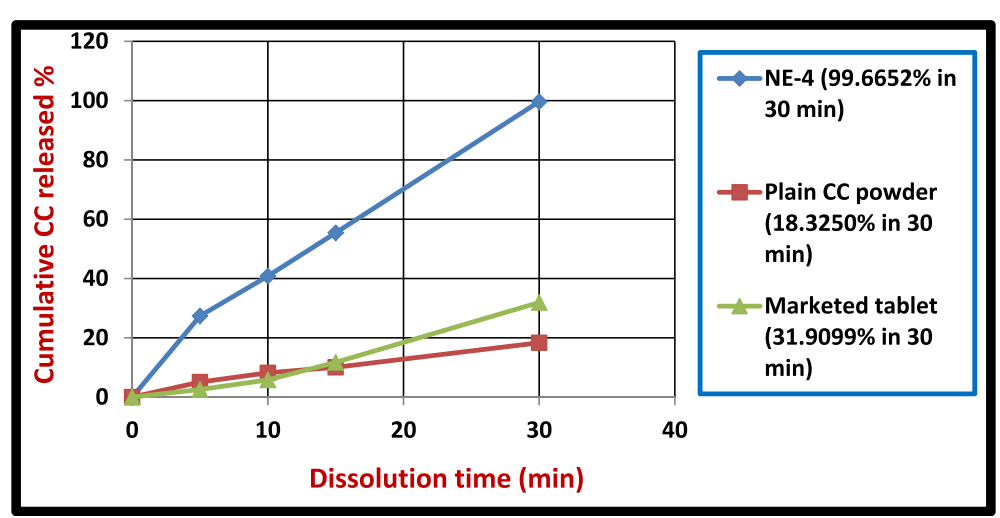

Fig. 9 A comparative dissolution profile of optimum candesartan cilexetil nanoemulsion relative to plain candesartan cilexetil powder and marketed tablet in $900 \mathrm{ml}$ of $0.1 \mathrm{~N} \mathrm{HCl}$ dissolution medium (pH 1.2) with $0.5 \%$ tween 20 at $37^{\circ} \mathrm{C}$ 
Table 8 Release kinetics study of candesartan cilexetil form nanoemulsions

\begin{tabular}{|c|c|c|c|c|c|c|}
\hline \multirow[t]{2}{*}{ F-code } & \multirow{2}{*}{$\begin{array}{l}\text { Zero } \\
\text { order } \\
\left(R^{2}\right)\end{array}$} & \multirow{2}{*}{$\begin{array}{l}\text { First } \\
\text { order } \\
\left(R^{2}\right)\end{array}$} & \multirow{2}{*}{$\begin{array}{l}\text { Higuchi } \\
\left(R^{2}\right)\end{array}$} & \multicolumn{3}{|c|}{ Korsmeyer and Peppas } \\
\hline & & & & $\overline{R^{2}}$ & $n$ & Release mechanism \\
\hline $\mathrm{NE}-1$ & 0.9939 & 0.6995 & 0.8857 & 0.9675 & 1.3013 & Supercase II transport \\
\hline $\mathrm{NE}-2$ & 0.9965 & 0.6420 & 0.9344 & 0.9549 & 1.2658 & Supercase II transport \\
\hline NE-3 & 0.9853 & 0.5978 & 0.9586 & 0.9392 & 1.2949 & Supercase II transport \\
\hline$N E-4$ & 0.9895 & 0.6538 & 0.9518 & 0.9400 & 1.4131 & Supercase II transport \\
\hline NE-5 & 0.9801 & 0.5737 & 0.9701 & 0.9253 & 1.2888 & Supercase II transport \\
\hline NE-6 & 0.9893 & 0.6409 & 0.9247 & 0.9504 & 1.2765 & Supercase II transport \\
\hline $\mathrm{NE}-7$ & 0.9863 & 0.6775 & 0.9369 & 0.9708 & 1.2271 & Supercase II transport \\
\hline NE-8 & 0.9957 & 0.6597 & 0.9132 & 0.9539 & 1.2432 & Supercase II transport \\
\hline Marketed & 0.9838 & 0.8426 & 0.9151 & 0.9707 & 1.0408 & Supercase II transport \\
\hline
\end{tabular}

diffraction technique. This is may be reasoned to agglomeration of cinnamon oil droplets placed on a glass slide of the SPM instrument in addition to the small volume of the loaded sample (Eyjolfsson 2015).

\section{Stability study}

The main advantage of nanoformulation, as in our case, is its stability. Actually, due to its small size, and in the case of (NE-4) the cinnamon oil droplets behave typically as Brownian particles and do not interact with each other, resulting in their stability, for up to several months (Wooster et al. 2008). The NE-4 did not change in visible appearance i.e., there was no flocculation, stratification, precipitation, creaming or cracking. This may be attributed to the fact that the NE formation and stability are not affected by ionic strength or $\mathrm{pH}$ changes due to the presence of non-ionic surfactants (Ozturk et al. 2014).
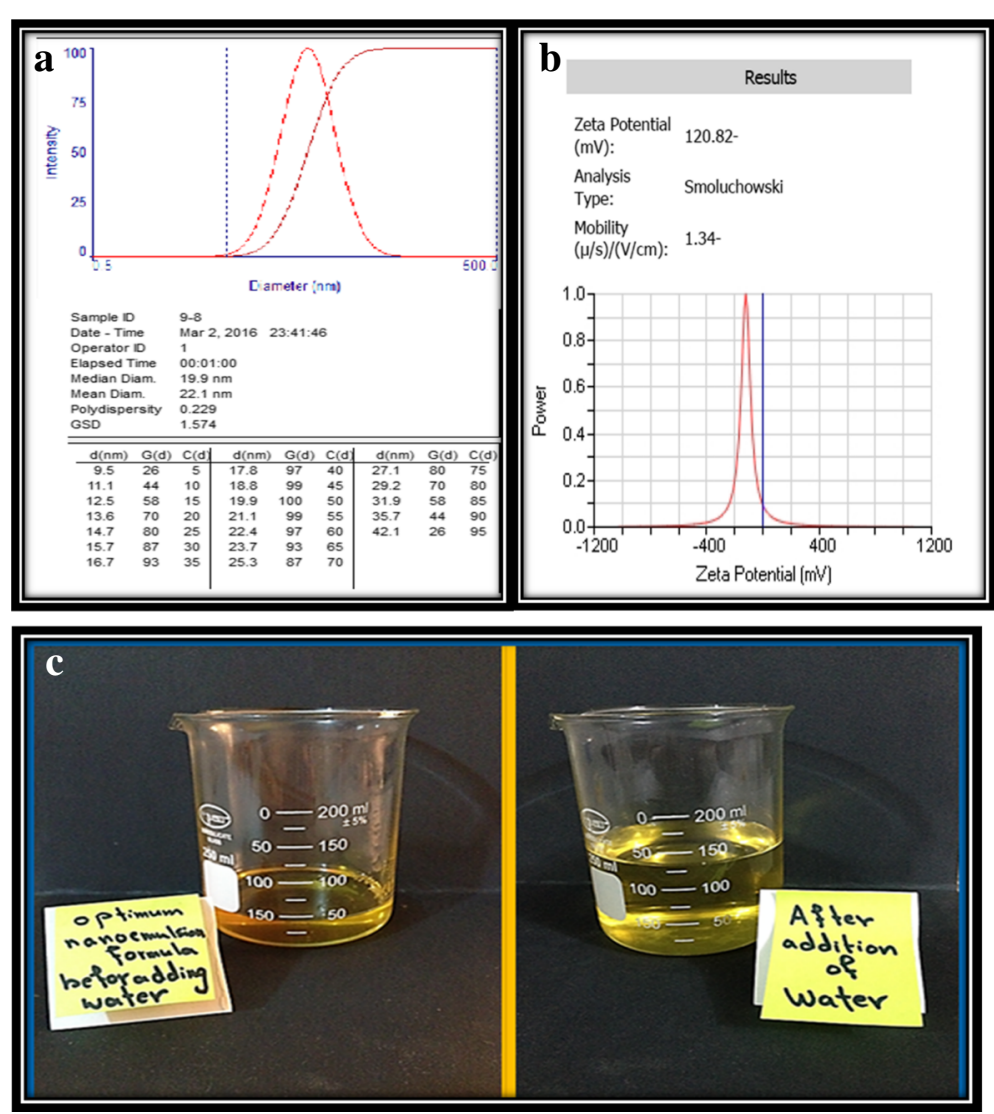

Fig. 10 Characteristics of optimum nanoemulsion formula (NE-4) showing: a Droplet size distribution, b Zeta potential, and c Physical appearance 

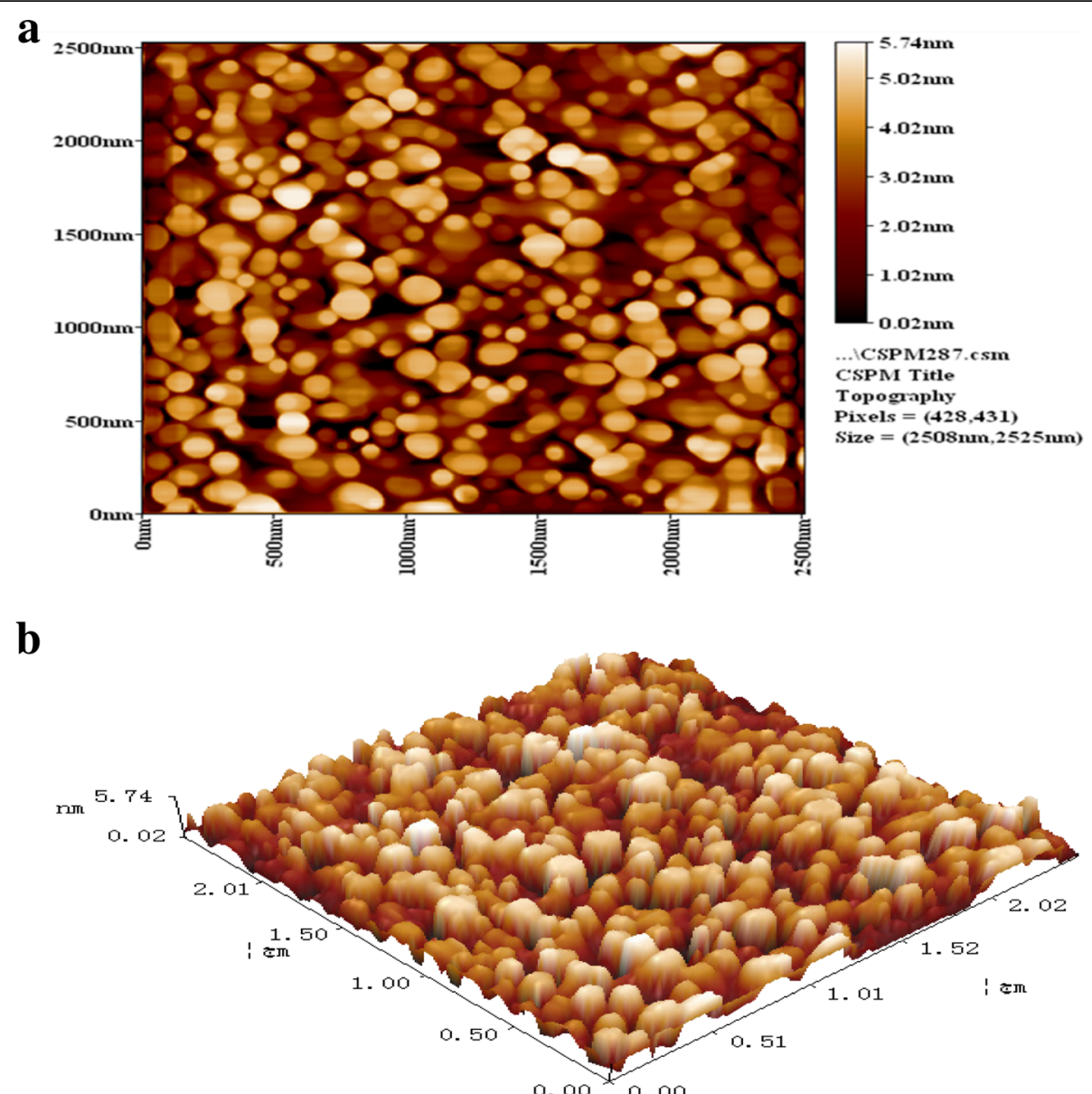

Fig. 11 Scanning probe microscopic image of optimum candesartan cilexetil nanoemulsion (NE-4) as: a Two dimensional topography (scope of image: $2508 \mathrm{~nm} 2525 \mathrm{~nm}$ ), and $\mathbf{b}$ Three dimensional section of candesartan cilexetil nanodroplet

The results are given in (Table 9) imply that there were no obvious changes in droplet size distribution, PDI, zeta potential and other physiochemical properties. It could be judged from the results gained, that poloxamer 407 adsorb strongly onto the surface of the nanodroplet via their hydrophobic polyoxypropylene center block and have been shown to be quite successful in regard to stabilization of NE droplet (Loureiro et al. 2015). Additionally, expiration date of CC loaded NE-4 was found to be (2.589 years).

Table 9 Stability of candesartan cilexetil optimum nanoemulsion formula (NE-4)

\begin{tabular}{|c|c|c|c|}
\hline \multirow[t]{2}{*}{ Test } & \multicolumn{3}{|c|}{ Results at temperature $40^{\circ} \mathrm{C}$} \\
\hline & Initial value & After 1 month & After 3 months \\
\hline Droplet size $(\mathrm{nm})$ & 22.1 & 22.7 & 24.6 \\
\hline PDI & 0.229 & 0.275 & 0.241 \\
\hline Zeta potential (mV) & -120.82 & -115.68 & -104.38 \\
\hline Transmittance \% & $99.8433 \pm 0.2081$ & $99.7333 \pm 0.1527$ & $98.6000 \pm 0.1000$ \\
\hline $\mathrm{pH}$ & $5.0966 \pm 0.2630$ & $5.0666 \pm 0.0585$ & $5.0533 \pm 0.0208$ \\
\hline $\mathrm{Rl}$ & $1.3931 \pm 0.0013$ & $1.3783 \pm 0.0003$ & $1.3728 \pm 0.0004$ \\
\hline Surface tension (mN/m) & 45.31 & 44.33 & 44.28 \\
\hline Conductivity $(\mu \mathrm{s} / \mathrm{cm})$ & 181.0666 & $181.1333 \pm 0.2854$ & $181.1666 \pm 0.3055$ \\
\hline Viscosity(mPa.s) & $23.0333 \pm 1527$ & $22.9333 \pm 0.6658$ & $22.5666 \pm 0.9609$ \\
\hline Dissolution & $99.6652 \pm 0.3226$ & $99.4279 \pm 0.0572$ & $98.1649 \pm 0.0002$ \\
\hline
\end{tabular}




\section{Conclusion}

The knowledge accumulated from this research far suggests that NEs offer advantages in producing an unprecedented enhancement in CC solubility and dissolution in term of rate and extent to a great value than the conventional tablet. It was apparent that deserved success of designing NE product is underpinned by applying the principle of regulating the HLB value. The optimum NE formula (NE-4) was a mixture of $3.030 \% \mathrm{w} / \mathrm{w}$ of cinnamon oil, $16.3632 \% \mathrm{w} / \mathrm{w}$ of tween $80,4.0908 \% \mathrm{w} / \mathrm{w}$ of poloxamer 407, $6.818 \% \mathrm{w} / \mathrm{w}$ of transcutol HP and $69.696 \% \mathrm{w} / \mathrm{w}$ of deionized water. This NE-drug delivery system is very physiochemically stable and showed to be a promising strategy to confront problems associated with chronic cardiovascular diseases old dosage forms, which necessitates a further study to prove their efficiency inside human harsh environmental conditions.

\begin{abstract}
Abbreviations
$\mu \mathrm{m}$ : Micro meter; $\mu \mathrm{s} / \mathrm{cm}$ : Microsiemens/centimeter; $\mu \mathrm{m} / \mathrm{s}$ : Micro meter per second; ANOVA: Analysis of variance; AT1: Angiotensin II type-1; CC: Candesartan cilexetil; Da: Dalton; g: Gram; GIT: Gastro intestinal tract; GRAS: Generally regarded as safe; HLB: Hydrophilic/lipophilic balance; h: Hour; Kg: Kilogram; Log P: Base-10 logarithm of the permeability coefficient; mg: Milligram; min: Minute; ml: Milliliter; mm: Millimeter; mN/ m: Milli newton per meter; mPa. s: Millipascal per second; $\mathrm{mV}$ : Millivolt; Mw: Micro watt; MWT: Molecular weight; N: Normal; NEs: Nanoemulsions; nm: Nanometer; No.: Number; o/w: Oil in water; Pa: Pascal; PDI: Polydispersity index; $\mathrm{pH}$ : Minus logarithm $\left[\mathrm{H}^{+}\right]$; PKa: Negative base-10 logarithm of the acid dissociation constant of a solution; RH: Relative humidity; RI: Refractive index; rpm: Revolution per minute; SD: Standard deviation; Smix: Surfactant/cosurfactant mixture; SPM: Scanning probe microscopy; USP: United state pharmacopeia; UV/Vis: Ultraviolet/visible; w/o: Water in oil; w/w \%: Weight by weight percent; $\zeta$ : Zeta potential; $\lambda_{\text {max }}$ : Wave length with maximum absorbance

\section{Funding}

None.
\end{abstract}

\section{Authors' contributions}

There is no individual contribution. Both authors read and approved the final manuscript.

\section{Competing interests}

The authors declare that they have no competing interests.

\section{Publisher's Note}

Springer Nature remains neutral with regard to jurisdictional claims in published maps and institutional affiliations.

Received: 24 January 2017 Accepted: 9 May 2017

Published online: 02 June 2017

\section{References}

Agubata CO, Nzekwe IT, Obitte NC, Ugwu CE, Attama AA, Onunkwo GC (2014) Effect of oil, surfactant and co-surfactant concentrations on the phase behavior, physicochemical properties and drug release from self-emulsifying drug delivery systems. J Drug Discov Develop Deliv 1(1):1-7

Ahmad J, Mir SR, Kohli K, Chuttani K, Mishra AK, Panda AK, Amin S (2014) Solid-nanoemulsion preconcentrate for oral delivery of paclitaxel: formulation design, biodistribution, and $\gamma$ scintigraphy imaging. BioMed Res Inter 2014:1-12.
Al-Nima AM, Al-Kotaji MM, Khayrallah AA (2014) Preparation and evaluation of meloxicam solid dispersions by solvent evaporation method. Int Res J Pharm 5(11):838-845

Americas IC (1984) The HLB, system: a time-saving guide to emulsifier selection. ICl Americas, Incorporated, USA

Ankith K, Reddy B, Niranjan BM (2013) Design, development and evaluation of novel a nanoemulsion of simvastatin. Int J Adv Pharm 3(2):94-101

Bandyopadhyay S, Bhuria L, Lal D (2013) An explicit review on quantitative estimation of candesartan cilexetil employing various analytical techniques. Pharma Anal Acta 4(6):1-7. doi:10.4172/2153-2435.1000254

Banker GS, Siepmann J, Rhodes C (2002) Modern pharmaceutics. CRC Press, New York

Beale JM, Block J, Hill R (2010) Organic medicinal and pharmaceutical chemistry. 12th ed. Lippincott Williams and Wilkins, Philadelphia

Bhatt P, Madhav S (2011) A detailed review on nanoemulsion drug delivery system. Int J Pharm Sci Res 2(9):2292-2298

Bruschi ML (2015) Strategies to modify the drug release from pharmaceutical systems, 2nd ed. Woodhead Publishing, London

Budavari S, O'Neil MJ, Smith A, Heckelman PE (1989) The merck index. Rahway, Merck

Darwhekar GN, Jain DK, Chouhan J (2012) Biopharmaceutical classification of candesartan and candesartan cilexetil. Asi J Pharm Life Sci 2(2):295-302

Desai SA, Mohite A, Hajare AA (2015) Screening of safflower oil microemulsion for enhancing bioavailability of lovastatin. Int J Pharm Sci Res 6(1):29-49

Dhawan B, Aggarwal G, Harikumar SL (2014) Enhanced transdermal permeability of piroxicam through novel nanoemugel formulation. Int J Pharm investing 4(2):65-76. doi:10.4103/2230-973X.133053

Díaz-Blancas V, Medina DI, Padilla-Ortega E, Bortolini-Zavala R, Olvera-Romero M, Luna-Bárcenas G (2016) Nanoemulsion formulations of fungicide tebuconazole for agricultural applications. Molecules 21(1271):1-12. doi:10. 3390/molecules21101271

Domalapally S, Revathi Al, Jaya S, Teja ND (2014) Enhancement of dissolution profile of poorly water soluble drug (nimodipine) by using liquisolid compact technique. Int J Pharma Sci 4(1):447-456

Eid AM, Elmarzugi NA, El-Enshasy HA (2013) Preparation and evaluation of olive oil nanoemulsion using sucrose monoester. Int J Pharm Pharm Sci 5(Suppl 3):434-440

Elnaggar YS, El-Massik MA, Abdallah OY (2009) Self-nanoemulsifying drug delivery systems of tamoxifen citrate: design and optimization. Int J Pharm 380(1): 133-141. doi:10.1016/j.jpharm.2009.07.015

Eyjolfsson R (2015) Design and manufacture of pharmaceutical tablets. Elsevier, London

Felton LA (2013) Remington-essentials of pharmaceutics, 1st ed. Pharmaceutical Press, London

Gupta RB, Kompella UB (2006) Nanoparticle technology for drug delivery. Taylor and Francis Group, New York

Gupta P, Pandit J, Ajay P, Swaroop P, Gupta S (2010) Pharmaceutical nanotechnology novel nanoemulsion-high energy emulsification preparation, evaluation and application. The Pharm Res 3:117-138

Gupta AK, Mishra DK, Mahajan SC (2011) Preparation and in-vitro evaluation of self emulsifying drug delivery system of antihypertensive drug valsartan. Int J Pharm Life Sci 2(3):633-639

Hassan AK (2015) Effective surfactants blend concentration determination for o/W emulsion stabilization by two nonionic surfactants by simple linear regression. Ind J Pharm Sci 77(4):461-469

Honary S, Zahir F (2013) Effect of zeta potential on the properties of nano-drug delivery systems-a review (Part 1). Trop J Pharm Res 12(2):255-264. doi:10. 4314/tjpr.v12i2.20

Husain A, Azim M, Mitra M, Bhasin PS (2011) A review on candesartan: pharmacological and pharmaceutical profile. J Appl Pharma Sci 1(10):12-17

Jain K, Kumar RS, Sood S, Gowthamarajan K (2013) Enhanced oral bioavailability of atorvastatin via oil-in-water nanoemulsion using aqueous titration method. J Pharm Sci Res 5(1):18-25

Jaiswal M, Dudhe R, Sharma PK (2015) Nanoemulsion: an advanced mode of drug delivery system. 3 Biotech 5(2):123-127. doi:10.1007/s13205-014-0214-0

Jampani N, Bonthu R, Reddy B (2012) Formulation and evaluation of candesartan cilexetil immediate release tablets. Int Res J Pharm 3(7):271-284

Kamalakkannan V, Puratchikody A, Ramanathan L (2013) Development and characterization of controlled release polar lipid microparticles of candesartan cilexetil by solid dispersion. Res in Pharm Sci 8(2):125-136

Kolesar JM, Vermeulen LC (2016) Top 300 Pharmacy Drug Cards-2016/2017. McGraw-Hill Education, New York 
Krishna HP, Srinivasan B, Rajamanickam D, Veerabhadraiah BB, Varadharajan M (2013) Solubility and dissolution enhancement of candesartan cilexetil by liquisolid compacts. Pharm Drug Deliv Res 2(2):1-10. doi:10.4172/2325-9604. 1000115

Kulshreshtha AK, Singh ON, Wall GM (2010) Pharmaceutical suspensions: from formulation development to manufacturing. Springer, New York

Kumar M, Pathak K, Misra A (2009) Formulation and characterization of nanoemulsion-based drug delivery system of risperidone. Drug Dev Indust Pharm 35(4):387-395. doi:10.1080/03639040802363704

Loureiro A, Nogueira E, Azoia NG, Sárria MP, Abreu AS, Shimanovich U, Rollett A Härmark J, Hebert H, Guebitz G, Bernardes GJ (2015) Size controlled protein nanoemulsions for active targeting of folate receptor positive cells. Colloids Surf B Biointerfaces 135:90-98. doi:10.1016/j.colsurfb.2015.06.073

Mahmoud H, Al-Suwayeh S, Elkadi S (2013) Design and optimization of selfnanoemulsifying drug delivery systems of simvastatin aiming dissolution enhancement. Afr J Pharm Pharmacol 7(22):1482-1500. doi:10.1155/2014/468456

Mandal A, Bera A (2012) Surfactant stabilized nanoemulsion: characterization and application in enhanced oil recovery. Int J Chem Mol Nuclear Mat Metallurgical Eng 6(7):537-542

Miastkowska M, Sikora E, Ogonowski J, Zielina M, Łudzik A (2016) The kinetic study of isotretinoin release from nanoemulsion. Colloids Surfaces $A$ Physicochem Eng Aspects 510:63-68. doi:10.1016/j.colsurfa.2016.07.060

Mishra RK, Soni GC, Mishra R (2014) Nanoemulsion: a novel drug delivery tool. Int J Pharma Res Rev 3(7):32-43

Moffat AC, Osselton MD, Widdop B (2011) Clarke's analysis of drugs and poisons, 4th ed. Pharmaceutical Press, London

Narang AS, Delmarre D, Gao D (2007) Stable drug encapsulation in micelles and microemulsions. Int J Pharmaceutics 345(1):9-25

Nasr AM, Gardouh AR, Ghonaim HM, Ghorab MM (2016) Design, formulation and in-vitro characterization of Irbesartan solid self-nanoemulsifying drug delivery system (S-SNEDDS) prepared using spray drying technique. J Chem Pharm Res 8(2):159-183

Ofokansi KC, Kenechukwu FC, Isah AB (2013) Poloxamer-stabilized topical miconazole nitrate-loaded microemulsion: formulation, design and characterization. J Dispersion Sci Techno 34(11):1563-1574. doi:10.1080/ 01932691.2012 .752713

Ozturk B, Argin S, Ozilgen M, McClements DJ (2014) Formation and stabilization of nanoemulsion-based vitamin E delivery systems using natural surfactants: Quillaja saponin and lecithin. J Food Engineering 142:57-63. doi:10.1016/j. jfoodeng.2014.06.015

Patel VP, Desai TR, Chavda BG, Katira RM (2011) Extemporaneous dosage form for oral liquids. Pharmacophore 2(2):86-103

Poornima V, Krishna SA (2016) Microemulsions-a potential carrier for drug delivery. Innovare J Life Sci 4(2):1-5

Pratiwi L, Fudholi A, Martien R, Pramono S (2016) Design and optimization of self-nanoemulsifying drug delivery systems (SNEDDS) of ethyl acetate fraction from mangosteen peel (Garcinia mangostana, L.). Int J PharmTech Res 9(6):380-387

Raavi S, Subramanian S, Vuddisa SK (2014) Supersaturated self nanoemulsifying tablets of atorvastatin. World J Pharm Pharm Sci 3(11):1275-1286

Rao BC, Vidyadhara S, Sasidhar RL, Chowdary YA (2015) Formulation and evaluation of liquid loaded tablets containing docetaxel-self nano emulsifying drug delivery systems. Trop J Pharm Res 14(4):567-573. doi:10. 4314/tjpr.v14i4.2

Rowe RC, Sheskey PJ, Weller PJ (2006) Handbook of pharmaceutical excipients, 6th ed. Pharmaceutical press, London

Sainsbury F, Zeng B, Middelberg AP (2014) Towards designer nanoemulsions for precision delivery of therapeutics. Curr Opin Chem Eng 4:11-17

Sarkar B, Hardenia S (2011) Microemulsion drug delivery system: for oral bioavailability enhancement of glipizide. J Adv Pharm Educ Res 1(4):195-200

Sarker DK (2013) Pharmaceutical emulsions: a drug developer's toolbag. John Wiley and Sons, London

Schuh RS, Bruxel F, Teixeira HF (2014) Physicochemical properties of lecithinbased nanoemulsions obtained by spontaneous emulsification or highpressure homogenization. Quim Nova 37(7):1193-1198. doi:10.5935/01004042.20140186

Selvam PR, Kulkarni PK, Dixit M (2013) Preparation and evaluation of selfnanoemulsifying formulation of efavirenz. Ind J Pharm Edu Res 47(1):47-54

Seo JW, Kim KJ, Kim SH, Hwang KM, Seok SH, Park ES (2015) Effect of process parameters on formation and aggregation of nanoparticles prepared with a shirasu porous glass membrane. Chem Pharm Bull 63(10):792-798
Setya S, Talegonkar S, Razdan BK (2014) Nanoemulsions: Formulation methods and stability aspects. World J Pharm Pharm Sci 3(2):2214-2228

Sharma B, Sharma A, Arora S, Gupta S, Bishnoi M (2012) Formulation, optimization and evaluation of atorvastatin calcium loaded microemulsion. J Pharm Drug Deliv Res 1(3):1-7. doi:10.4172/2325-9604.1000109

Shukla SN, Modi DC, Shah DP (2016) A review on solid self-nanoemulsifying drug delivery system: an approach for bioavailability enhancement. World J Pharm Pharm Sci 5(5):302-316

Souto EB, Nayak AP, Murthy RS (2011) Lipid nanoemulsions for anti-cancer drug therapy. Die Pharmazie-An Int J Pharm Sci 66(7):473-478. doi:10.1691/ph. 2011.0392

Srilatha R, Aparna C, Srinivas Prathima SM (2013) Formulation, evaluation and characterization of glipizide nanoemulsion. Asi J Pharm Clin Res 6(Suppl 2):66-71

Strickley RG (2004) Solubilizing excipients in oral and injectable formulations. Pharm Res 21(2):201-230. doi:10.1023/B:PHAM.0000016235.32639.23

Sureshkumar R, Gowthamarajan K, Bhavani P (2015) Nanoemulsion for lymphatic absorption: investigation of fenofibrate nanoemulsion system for lymphatic uptake. Int J ChemTech Res 7(2):832-841

Sweetman SC (2009) Martindale: the complete drug reference, 36th ed. Pharmaceutical press, London

Talegaonkar S, Tariq M, Alabood RM (2011) Design and development of o/w nanoemulsion for the transdermal delivery of ondansetron. Bulletin of Pharm Res 1(3):18-30

Thassu D, Deleers M, Pathak YV (2007) Nanoparticulate drug delivery systems. Informa Healthcare, New York

Tiwari SB, Amiji MM (2006) Improved oral delivery of paclitaxel following administration in nanoemulsion formulations. J Nanosci Nanotechnol 6(8):17. doi:10.1166/jnn.2006.440

Troncoso E, Aguilera JM, Mc Clements DJ (2011) Development of nanoemulsions by an emulsification-evaporation technique. 92.

Vishnu P, NaveenBabu K, Reddy MS (2015) Formulation and evaluation of candesartan cilexetil floating tablets by melt granulation technique. Int J Res in Pharm Chem 5(2):373-379

Vuddisa SK, Subramanian S, Raavi S (2014) Preparation and characterization of candesartan cilexetil solid lipid nanoparticulate capsules. Int J Pharma Res Rev 3(12):26-31

Wais M, Samad AB, Khale AN, Aqil MO, Khan M (2012) Investigation of nanoemulsion system for transdermal delivery of glibenclamide. Int J Pharm Pharm Sci 4(4):482-487

Wooster TJ, Golding M, Sanguansri P (2008) Impact of oil type on nanoemulsion formation and Ostwald ripening stability. Langmuir 24(22):12758-12765. doi: 10.1021/la801685v

Xu J, Yang B, Hammouda B (2011) Thermal conductivity and viscosity of selfassembled alcohol/polyalphaolefin nanoemulsion fluids. Nanoscale Res Lett 6(274):1-6

Yadav PS, Yadav E, Verma A, Amin S (2014) Development, characterization, and pharmacodynamic evaluation of hydrochlorothiazide loaded selfnanoemulsifying drug delivery systems. Scientific World J. 1-10. doi:10.1155/ 2014/274823.

Yasser M, Gad S, El-sayed M, Ghorab M (2013) The effect of converting liquid valsartan SNEDDS into solid SNEDDS using different solid carriers on its performance. Int J Bio Pharm Res 4(12):1015-1026

Zhang Y, Lam YM (2006) Study of mixed micelles and interaction parameters for polymeric nonionic and normal surfactants. J Nanosci Nanotechnol 6(12): 3877-3881. doi:10.1166/jnn.2006.673 